\title{
PITFALLS IN THE ALARM CHAIN: Assessing the feasibility of 'silent' intravenous pumps in a paediatric oncology ward
}

\author{
Yvonne van der Wal BSc., Drs. E. Koomen, Dr. M.R. Spruit
}

\section{Utrecht University}

\section{Introduction}

The aim of the silent pump project is to create an alarm-free environment for the patient and their family during treatment.

This study assesses the feasibility of sending perfusion and volumetric pump alarms directly to the pager of the professional while the device remains silent in the patient room. This is expected to increase sleep quality, decrease alarm fatigue, and improve workflow.

\section{Methods}

The table shows the phases of the silent pump project. An extensive risk assessment following ISO-guidelines was performed for all phases. Four professionals were interviewed and the work process of responding nurses was observed on two occasions. Exploratory data analys is was performed on pump, monitor and pager data. The study took place in the Paediatric Oncology ward, Princess Maxima Centre.

\section{Discussion}

Alarm overload is of great concern in hospitals using a devicepager alarm chain. Several severe pitfalls worsening alarm overload were discovered in the current hospital alarming system. These can potentially be improved by educating professionals on alarm hygliene and by differentiating allarms. Chances of a successful implementation of silent pumps may increase after current risks are addressed.

\begin{tabular}{|c|c|c|c|}
\hline Phase & Data & Pump device & Pager \\
\hline $\mathbf{0}$ & & $(((\Omega)))$ & \\
\hline $\mathbf{1}$ & & $(((\Omega)))$ & \\
\hline $\mathbf{2}$ & & $(((\Omega)))$ & $(((\Omega)))$ \\
\hline $\mathbf{3}$ & & & $(((\Omega)))$ \\
\hline
\end{tabular}

\section{Risk assessment results}

The current alarming system used in many hospitals poses several severe risks concerning alarm overload, classified into four categories:

- Device alarms can only be turned off in the patient room;

- Staff setting alarm sensitivity unnecessarily high;

- Patient moving around leads to many disconnection alarms;

- Patient is unnecessarily connected to a device.

\section{Data analysis results}

- The average response time for alarms only sounding on the pump device is 77 seconds versus 18 seconds when alarms also sound on the pager: a 59 seconds decrease (fig. 1);

- Fig. 1 shows a clear difference in alarm response behavior;

- Parents of patients mute alarms when they only sound on the pump device (fig. 2). This effect falls away when the alarm also sounds on the pager.

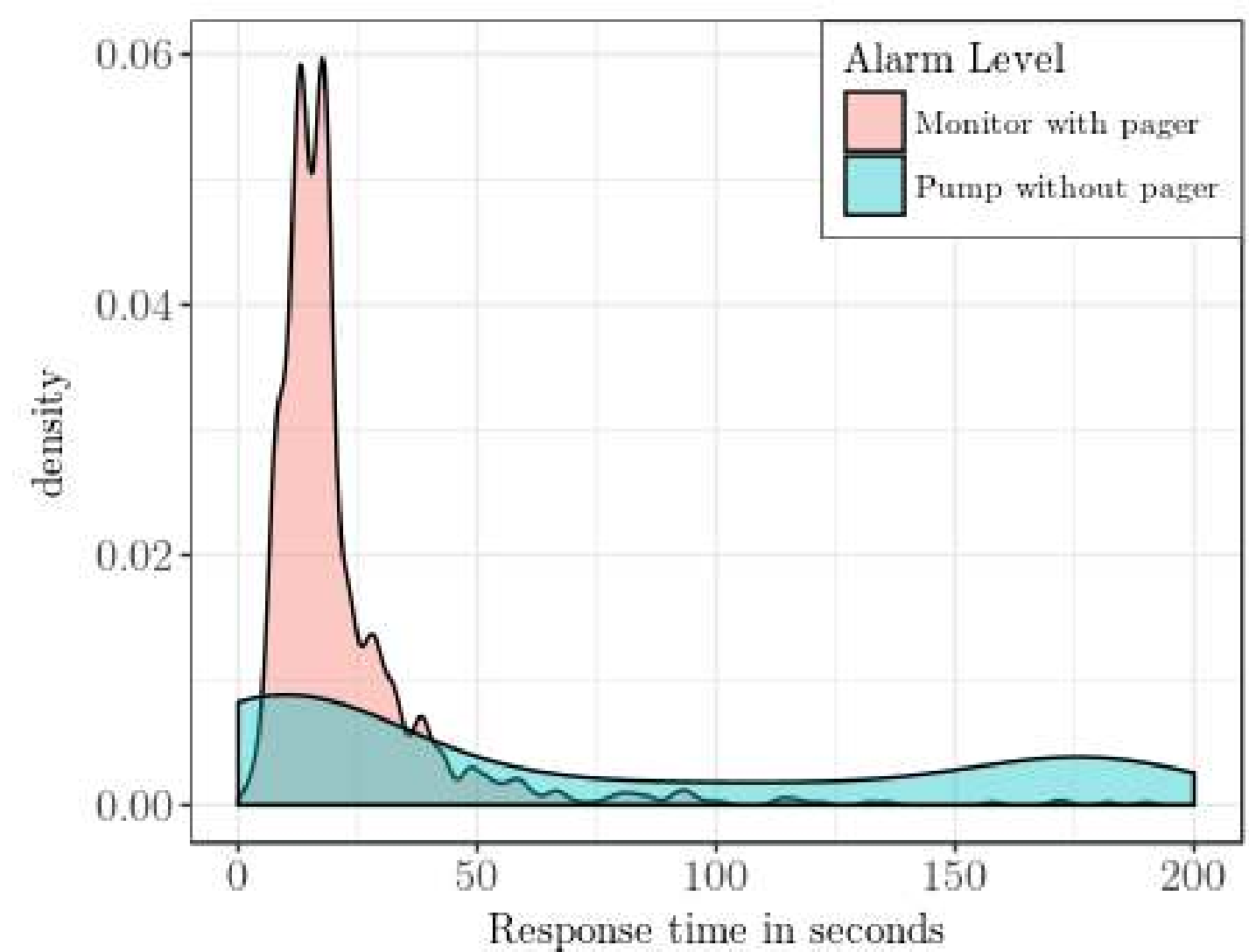

Figure 1. Difference in response pattern after alarm switch.

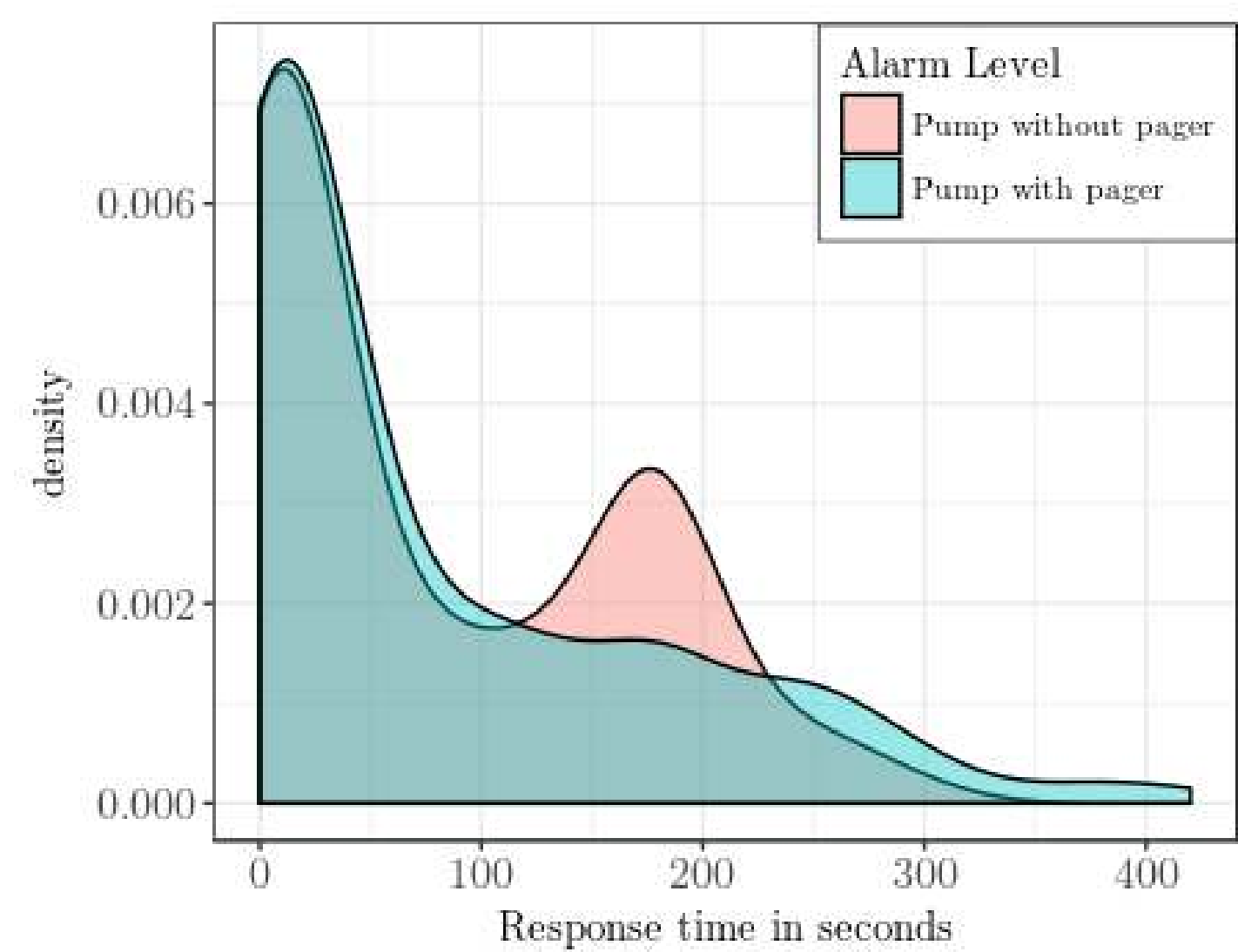

Figure 2. Difference in alarm muting after alarm switch.

Copyright @ 2018 Yvonne van der Wal, y.vanderwal@uu.nl +31611295640. 